\title{
Opinion on Different Findings in Experimental and Clinical Medicine
}

\section{Felix-Martin Werner ${ }^{1,2 *}$ and Rafael Coveñas ${ }^{2}$}

${ }^{1}$ Higher Vocational School of Elderly Care and Occupational Therapy, Euro Academy Pößneck, Pößneck, Thuringia, 07381, Germany

'Laboratory of Neuroanatomy of the Peptidergic Systems (Lab. 14), Institute of Neurosciences of Castilla y León (INCYL), University of Salamanca, Castilla-León, 37007-Salamanca, Spain

In this paper we are giving a brief account on Volume 8 Issue 4 , it contains different opinions, research articles, case reports and minireviews about experimental and clinical themes and about dementia. Singh wrote the following editorial entitled: "Oxidative Stress and Neurodegeneration". Oxidative stress is responsible for the death of microglia and astrocytes and this is due to an imbalance between production and deactivation of reactive nitrogen species and reactive oxygen species. Free radicals with unpaired electrons in the outer orbit are very reactive and induce excitotoxicity. Hydrogen peroxide and peroxynitrite are not directly toxic to cells, but are further metabolized. There are some antioxidant species that can counteract free radicals, for example vitamins $\mathrm{A}, \mathrm{C}$ and $\mathrm{E}$ and enzymes like glutathione and superoxide dismutase. Hydrogen peroxide can induce cell damage, for example to some proteins and unsaturated fatty acids and promotes cell apoptosis. Oxidative stress is important in the pathogenesis of neurodegenerative diseases such as Alzheimer's and Parkinson's disease [1].

Werner, who is currently working at the Euro Academy Pößneck (Germany), presents three cases of schizoaffective disorder and different pharmacological interventions. Schizoaffective disorder is a serious mental disease with schizophrenic and affective, i.e. depressive, manic or bipolar symptoms. All three patients showed schizoaffective symptoms with bipolar or manic symptoms in a recurrent form. They finally are treated with second-generation antipsychotic drugs such as clozapine, olanzapine or quetiapine. The first patient was additionally treated with two mood-stabilizing drugs [2].

Paovic et al. [3] presents the research article entitled "Correlation between Epiretinal Membrane Bridging, Visual Acuity and Central Macular Thickness". The aim of the presented study was to determine to what extent the epiretinal membrane, that bridges or not bridges the fovea, exerts an influence on the visual acuity. The authors examined 188 eyes with epiretinal membranes of 138 patients. The analysis showed that in both groups (epiretinal membranes or without a epiretinal membrane bridging the fovea), there was no significant difference on the visual acuity. The authors observed that a relationship between epiretinal membrane that bridges the fovea and the central macular thickness occurred [3].

De Sanctis et al. present the review article: "Osteosarcoma in Dogs: Diagnosis and Treatment - A Literature Review”. Osteosarcoma is the most frequent primary bone tumor in dogs. Osteosarcoma is a very aggressive tumor, which above all metastases in the lungs. Therefore, this tumor has a bad prognosis. Cancer-therapy is done by an operation and combined radio - and chemo-therapy. De Sanctis et al. undertook a survey of the current literature in order to show the biological bases for physicians to improve diagnostic and therapeutic methods [4].

El-Aleem et al. present the research article: "Co-upregulation of Transforming Growth Factor Beta-1 and Nitric Oxide Synthase in Keloid by Comparison to Normal Human Skin - A Possible Role for TGF $\beta 1$ and NOS in Pathogenesis of Keloid". Keloid is a disabling form of wound healing with skin fibrosis. Transforming growth factor beta (TGFß) and nitric oxide (NO) are active biomarkers which indicate the phase of the wound healing and are associated with fibrosis. TGBß and Nitric Oxide Synthase synthesizing NO have respectively three isoforms. The authors hypothesize that TGFß and NO are associated with excessive collagen deposition in fibrotic disorders such as keloid disease. The authors examined the isoforms of TGFß and nitric oxide synthase in keloid tissue. In keloid, above all a co-upregulation of TGFß1 and inducible nitric oxide synthase was found. This research article is of great importance, because it gives the possibility to develop a specific antifibrotic pharmacological agent [5].

Hazifur et al. presents the image article entitled: "Cinnamic Acid Enhances Glucose-stimulated Insulin Secretion in MIN6 Cells “. MIN6 cells were incubated with and without cinnamic acid. Cells were then incubated with anti-insulin antibodies, and an immunofluorescence technique was performed. In absence of cinnamic acid, insulin staining was concentrated around the nucleus, whereas after incubation with cinnamic acid, insulin staining was decreased and dispersed throughout the cell. Consequently, cinnamic acid enhanced glucosestimulated insulin secretion in MIN6 cells. This is an important step in finding new therapies for the treatment of diabetes mellitus type 2 [6].

Alnaji writes the opinion: “Stem Cells, What is Behind?". The author is a neurosurgeon and has been working on introducing stem cells into practical medicine for seven years. In his opinion, the reason why the transplantation of stem cells in some cases faces with complications is due to intercellular bacteria, for example Brucella. Thus, it is important to perform a PCR diagnosis of the transplanted tissues or blood [7].

Fatima et al. Present the research article: "Modulation of Pancreatic $\beta$-Cells and Antioxidant Status by Cinnamon in Type 2 Diabetic Rats". In non-obese diabetic adult Wistar rats, the authors form two experimental groups. The first group is treated with cinnamom, the second group is administered with glibenclamide. Cinnamom exerts a good antidiabetic activity by increasing insulin secretion, modulatng ß-cell function and improving anti-oxidant status [8].

Hojouj et al. Write the case study: "Antioxidant Modulation of Hematological Toxicity during Chemotherapy for Breast Cancer". Adverse effects of anti-cancer drugs limit the therapeutic effect of most cytostatics. Chemotherapeutic agents increase, in various tissues, the

*Corresponding author: Werner FM, Medical Doctor, Dr. Med. Research Field: Neural Networks in Neurological and Psychiatric Diseases, University of Salamanca, Instituto de Neurociencias de Castilla y León (INCYL), Laboratorio de Neuroanatomía de los Sistemas Peptidérgicos (Lab. 14)/Pintor Fernando Gallego, 137007-Salamanca, Spain, Tel: +34/923/29 44 00, Extn. 1856; Fax: +34/923/294549; E-mail: felixm-werner@versanet.de

Received November 10, 2017; Accepted November 22, 2017; Published December 01, 2017

Citation: Werner FM, Coveñas R (2017) Opinion on Different Findings in Experimental and Clinical Medicine. J Cytol Histol 8: 487. doi: 10.4172/21577099.1000487

Copyright: (c) 2017 Werner FM, et al. This is an open-access article distributed under the terms of the Creative Commons Attribution License, which permits unrestricted use, distribution, and reproduction in any medium, provided the original author and source are credited. 
Citation: Werner FM, Coveñas R (2017) Opinion on Different Findings in Experimental and Clinical Medicine. J Cytol Histol 8: 487. doi: 10.4172/21577099.1000487

formation of free-radical processes and hence lipid peroxidation. It might be possible to reduce adverse effects induced by cytostatics by additionally administering drugs exerting an antioxidant action [9].

In Alzheimer's disease, Werner presents a mini-review about the use of agonists or antagonists of specific serotonergic receptors for the treatment of the cognitive symptoms. In Alzheimer's disease, hypoactivity of muscarinic cholinergic, serotonergic and GABAergic neurons and hyperactivity of nordrenergic and excitotoxic glutamatergic neurons have been reported in the hippocampus and prefrontal cortex. Neural networks in the brain regions considering the mentioned neurotransmitters are described. Animal experiments and first clinical triasl of the cognition enhancing effect of $5-\mathrm{HT}_{4}$ and 5- $\mathrm{HT}_{7}$ agonists and 5- $\mathrm{HT}_{3}$ and $5-\mathrm{HT}_{6}$ antagonists are presented. The development of a hybrid combining GABA agonists and NMDA antagonists is suggested [10].

Kim SH et al. Present the case report: "Primary Renal Myxofibrosarcoma in a Woman: A Case Report and Literature Review". The authors present the case of a 45 -year old woman with an abdominal tumor originated from the right kidney. The tumor was diagnosed as a myxofibrosarcoma. The renal tumor was extirpated. On a routine abdominal CT (computed tomography) three months later, no new abdominal metastasis was found and no additional systemic therapy was performed [11].

\section{References}

1. Singh SK (2017) Oxidative Stress and Neurodegeneration. J Cytol Histol 8: 4.
2. Werner FM (2017) Three Cases of Schizoaffective Disorder: Different Pharmacological Interventions. J Cytol Histol 8: 4.

3. Paovic J, Paovic P, Paovic AS (2017) Correlation between Epiretinal Membrane Bridging, Visual Acuity and Central Macular Thickness J Cytol Histol 8: 4.

4. De Sanctis P, Ramos Caetano BF, Montaya Floréz LM, de Souza VB Zambuzzi WF, et al. (2017) Osteosarcoma in Dogs: Diagnosis and Treatment - A Literature Review. J Cytol Histol 8: 4.

5. El-Aleem SA, Abdelwahab S, Saber Osman NM (2017) Co-upregulation of Transforming Growth Factor Beta-1 and Nitric Oxide Synthase in Keloid by Comparison to Normal Human Skin - A Possible Role for TGF 11 and NOS in Pathogenesis of Keloid. J Cytol Histol 8: 4.

6. Hafizur RM, Raza SA, Maryam K, Fatima N, Hammed A (2017) Cinnamic Acid Enhances Glucose-stimulated Insulin Secretion in MIN6 Cells. J Cytol Histol 8: 4 .

7. Alnaji A (2017) Stem Cells, What is behind? J Cytol Histol 8: 4

8. Fatima N, Khaleeq A, Momin S, Waraich RS, Khaliq S, et al. (2017) Modulation of Pancreatic $\beta$-Cells and Antioxidant Status by Cinnamon in Type 2 Diabetic Rats. J Cytol Histol 8: 4.

9. Hojouj M, Bondarenk I, Zavizion V, Artemnko M, Soloviova N, et al. (2017) Antioxidant Modulation of Hematological Toxicity during Chemotherapy for Breast Cancer. J Cytol Histol 8: 4.

10. Werner FM (2017) Specific Agonists and Antagonists of Serotonergic Receptors in the Treatment of Cognitive Symptoms in Alzheimers Disease. J Cytol Histol 8: 4.

11. Kim SH, Suh YS, Kim JK, Park WS, Park SY, et al. (2017) Primary Renal Myxofibrosarcoma in a Woman: A Case Report and Literature Review. J Cytol Histol 8: 4 